\title{
FORMULATION AND EVALUATION OF AN ANTIMICROBIAL MUCOADHESIVE DENTAL GEL OF AZADIRACHTA INDICA AND GLYCYRRHIZA GLABRA
}

\author{
HEMANT K. JAIN*, PRERANA N. SWAMI, K. N. GUJAR
}

Department of Quality Assurance Techniques, Sinhgad College of Pharmacy, Vadgaon (Bk.), Pune 411041, Maharashtra, India Email: hemantkjain2001@yahoo.co.in

Received: 12 Sep 2018, Revised and Accepted: 30 Jan 2019

\begin{abstract}
Objective: Objective of this study was to formulate and evaluate an antimicrobial mucoadhesive dental gel of herbal drugs for the prevention and treatment of dental plaque, dental caries, and periodontitis.

Methods: Azadirachta indica leaves extract was prepared with ethanol: water $(80: 20 \mathrm{v} / \mathrm{v})$ and Glycyrrhiza glabra roots extract was prepared with ethanol: water $(30: 70 \mathrm{v} / \mathrm{v})$. Both the extracts were evaluated for organoleptic properties, $\mathrm{pH}$, phytochemical screening and total phenolic content. Thin layer chromatography (TLC) and Reverse-phase high-performance liquid chromatography (RP-HPLC) studies were performed. Antibacterial activity of the extract was done on Mueller Hinton agar media against Streptococcus mutans using the disc diffusion method. A mucoadhesive gel was prepared using carbopol 934, polyethylene glycol (PEG) 400 as a bioadhesive polymer and penetration enhancer, respectively. Three gel formulations were prepared at various concentrations of carbopol 934. Dental gel formulations were evaluated for different parameters such as appearance, $\mathrm{pH}$, viscosity, spreadabilty, syringeability. Optimised batch was used for further studies viz. stability study, drug content, diffusion study to determine percent cumulative release of drug from gel formulation and in vitro mucoadhesion study.
\end{abstract}

Results: Rf value of nimbin and glycyrrhizin in TLC study, were found to be 0.08 and 0.56 , respectively. RP-HPLC method was developed for estimation of active constituents present in both extracts using mobile phase acetonitrile: water [containing $0.1 \% \mathrm{v} / \mathrm{v}$ glacial Acetic acid (GAA)]: methanol in the ratio of 30:60:10 at the flow rate of $0.8 \mathrm{ml} / \mathrm{min}$. $\mathrm{R}_{\mathrm{t}}$ of active constituents from both drug extracts was found to be 3.119 and 4.15 min, respectively. $2.5 \% \mathrm{w} / \mathrm{v}$ of Azadirachta indica leaves extract showed a good zone of inhibition (10.66 $\pm 0.577 \mathrm{~mm})$ near to chlorhexidine $(11.33 \pm 0.5773 \mathrm{~mm}) .1 \%$ of Glycyrrhiza glabra roots extract exhibit antibacterial activity $(9 \pm 1 \mathrm{~mm})$ and masks the bitter taste of formulation. Batch (F2) was selected on the basis of viscosity, spreadabilty and syringeability. The optimised batch was found to be stable and has $83 \%$ and $80.3 \%$ of drug content. Percent cumulative releases of the drug from gel formulation during the diffusion study were found to be $87.52 \%$ and $85.43 \%$. Adhesive force and adhesiveness were found to be $11.90 \mathrm{~g}$ and 0.92 millijoule, respectively during mucoadhesion study.

Conclusion: The evaluation parameters of optimized batch indicate the prepared dental gel is mucoadhesive, stable, good delivery drug system containing antimicrobial agents for prevention of plaque formation, dental caries and periodontitis.

Keywords: Azadirachta indica, Glycyrrhiza glabra, Oral local drug delivery, Mucoadhesive gel, Carbopol 934

(C) 2019 The Authors. Published by Innovare Academic Sciences Pvt Ltd. This is an open access article under the CC BY license (http://creativecommons.org/licenses/by/4.0/) DOI: http://dx.doi.org/10.22159/ijap.2019v11i2.29723

\section{INTRODUCTION}

Teeth play an important role in breaking down of food material for proper digestion and overall nutrition. Dental diseases may occur without proper care of the teeth. Dental diseases are the most prevalent chronic diseases worldwide and a costly burden to health care services. The treatment of dental diseases is expensive, accounting for between $5 \%$ and $10 \%$ of total health care expenditures in industrialized countries [1]. Periodontal disease or periodontitis is the result of infections that lead to inflammation and tissue damage in the structures surrounding the teeth [2]. Periodontitis is the most common localized dental inflammatory disease related with several pathological conditions like inflammation of gums (gingivitis), degeneration of periodontal ligament, dental cementum and alveolar bone loss [3]. Tooth decay/dental caries/cavity are a breakdown of teeth due to acid made by bacteria like Streptococcus mutans. Dental caries has been the most common oral health problem in the world. Dental caries is defined as a localized, post-eruptive, pathological process of external origin involving softening of the hard tooth tissue and proceeding to the formation of a cavity. Untreated dental caries can affect the quality of life as a result of pain or discomfort, tooth loss, impaired oral functioning [4]. Dental caries is caused by the production of acid originated from bacteria fermenting carbohydrates leading to demineralization of the dental enamel and the formation of cavities. The bacteria are part of the oral biofilm also called the dental plaque residing on the dental enamel [5]. Plaque is a mixture of bacteria, minerals and some food residue. Some plaque hardens into calculus. Often, plaque and calculus do not come off with the brush and floss and cause inflammation, an ongoing state of gingivitis. Various preventive and treatment modalities are used in this perspective which includes oral hygiene, gingival irrigations and mechanical therapies like manual scaling and root planning, ultrasonic scalars and lasers. Mechanical instrumentation, full mouth disinfection, host modulation, and antimicrobial therapy are used in the non-surgical management of periodontal infections [6]. Undesired effects of antimicrobial chemicals and antibiotics create the interest of dental product manufacturers towards herbal drugs to avoid the side effects. Some studies suggested that the natural herbs can help to stop the development of periodontitis [7]. Potent antibacterial herbal drug Azadirachta indica leaves containing terpenoids like nimbin, nimbinin, nimbolide and nimbidin for prevention and treatment of dental plaque, dental caries and periodontitis $[8,38,39]$. Therefore, this drug was selected for the proposed work. However, the taste of Azadirachta indica is bitter and which requires taste masking. Some reports indicate that the glycyrrhizin has low-calorie value and 50 times sweeter than sucrose can masks the bitter taste of pharmaceuticals [9]. In this context, another drug Glycyrrhiza glabra was combined with Azadirachta indica. Local delivery of mucoadhesive gel formulation will increase the residence time of formulation, rapid absorption, improved patient compliance and ease of administration [10]. Therefore, the antimicrobial mucoadhesive dental gel was formulated.

\section{MATERIALS AND METHODS}

Dried Azadirachta indica leaves (Auth.18-11) and Glycyrrhiza glabra roots (Auth.18-12) were procured from Green Pharmacy, Pune, India. Both drugs were authenticated from Agharkar Research Institutes, Pune, India. Carbopol 934, polyethylene glycol (PEG 400), FolinCiocalteu reagent, methylparaben, propylparaben, triethanolamine, 
sodium carbonate, gallic acid and glacial acetic acid (GAA) were obtained from Loba Chemie Pvt. Ltd, Mumbai. Disodium hydrogen phosphate and potassium dihydrogen phosphate were procured from Merck Specialities Pvt. Ltd, Mumbai. Mueller Hinton agar media for the growth of bacteria was obtained from HiMedia Laboratories. Freeze dried culture of bacterial strain Streptococcus mutans was procured from Microbial Type Culture Collection (MTCC), Chandigarh.

\section{Instrument}

The analytical method was performed on Shimadzu HPLC (LC 2010 CHT, Japan) having a quaternary system with automatic injection facility, LC solution software, and UV visible detector. The column used was Purospher Star RP-18e, Hibar C-18 (250 mm x $4.6 \mathrm{~mm}, 5$ $\mu \mathrm{m})$. Shimadzu (UV-1800) UV-visible spectrometer, Bruker (Alpha-T model) FT-IR, Equiptronics (EQ-610) digital pH meter and Shimadzu (AX-200) analytical balance were employed for this study.

\section{Preparation of extracts}

\section{Preparation of Azadirachta indica leaves extract}

Selection of menstruum was based on a better yield of active constituents and safety. Dry powder of Azadirachta indica leaves (40 g) was macerated with ethanol: water $(80: 20 \mathrm{v} / \mathrm{v})$ for $48 \mathrm{~h}$ under the dark condition at $25-28{ }^{\circ} \mathrm{C}$ with occasional shaking and filtered through a muslin cloth and then filtered through Whatman filter paper $0.45 \mu$ [11]. Filtrate was concentrated, acidified and finally fractionated with chloroform. Separated chloroform fraction was dried and weighed which contains terpenoid components [12].

\section{Preparation of Glycyrrhiza glabra roots extract}

Dry powder of Glycyrrhiza glabra roots (40 g) was extracted with ethanol: water $(30: 70 \mathrm{v} / \mathrm{v})$ for $60 \mathrm{~min}$ at $50{ }^{\circ} \mathrm{C}$. The obtained menstruum was filtered through a muslin cloth and then filtered through Whatman filter paper $0.45 \mu$. The filtrate was dried [13].

\section{Physicochemical characteristics of extracts}

Both the extracts were evaluated for organoleptic properties like colour, odour, consistency, $\mathrm{pH}$ and phytochemical screening [14].

\section{Total phenolic content (TPC) of Azadirachta indica leaves extract}

The total phenolic content was determined by the Folin-Ciocalteu reagent (FCR) method [15]. Folin-Ciocalteu reagent and $6 \% \mathrm{Na}_{2} \mathrm{CO}_{3}$ solutions were prepared in distilled water. Aliquot of $200 \mu \mathrm{l}$ of the extract was dispensed in the tube. $1.5 \mathrm{ml}$ of $10 \%$ FCR was added to the tube followed by incubation for $5 \mathrm{~min}$ in the dark condition. Then, 1.5 $\mathrm{ml}$ of $6 \%$ sodium carbonate was added to the test tube and mixed thoroughly. The tube was incubated for $2 \mathrm{~h}$ in the dark condition and finally, absorbance was measured by UV-visible spectroscopy at 765 $\mathrm{nm}$ wavelength by using a UV-visible spectrophotometer.

\section{TPC of Glycyrrhiza glabra roots extract}

The total phenolic content in the root of Glycyrrhiza glabra was also determined by spectrophotometry using FCR method. The root extract $(200 \mu \mathrm{l})$ was mixed with $1 \mathrm{ml}$ of Folin-Ciocalteu reagent followed by incubation for $5 \mathrm{~min}$ in the dark condition. Then, $0.8 \mathrm{ml}$ of a $7.5 \%$ sodium carbonate was added to the test tube and mixed thoroughly. The tube was incubated for $30 \mathrm{~min}$ in the dark condition and finally, absorbance was measured by UV-visible spectroscopy at $765 \mathrm{~nm}$ wavelength by using a UV-visible spectrophotometer [16].

\section{Thin layer chromatography (TLC)}

Hexane: acetone (9:1 v/v) solvent system was used as a mobile phase for TLC study of Azadirachta indica leaves extract [17, 18]. Ethyl acetate: ethanol: water: ammonia (65:25:9:1 v/v) solvent system was used as a mobile phase for TLC study of Glycyrrhiza glabra roots extract [19].

\section{RP-HPLC method development}

\section{Selection of detection wavelength}

Suitable wavelength for the HPLC analysis was determined by recording UV spectra in the range of 200-400 $\mathrm{nm}$ for Azadirachta indica leaves and Glycyrrhiza glabra roots extract. Solutions of 10 $\mu \mathrm{g} / \mathrm{ml}$ concentration of both extracts were prepared in ethanol and water, separately and scanned in between 200 to $400 \mathrm{~nm}$ [20-22].

\section{Chromatographic conditions}

Stationary phase ODS Hibar C-18 column (250 mm x $4.6 \mathrm{~mm}, 5 \mu \mathrm{m}$ ) was used. Initially, various chromatographic conditions were tried in order to obtain better separation characteristics. Finally, the mobile phase containing acetonitrile: water (containing $0.1 \%$ GAA): methanol (30:60:10 v/v) was selected [21, 22].

\section{Preparation of the mobile phase}

Solvents (HPLC grade) of mobile phase (acetonitrile, $0.1 \% \mathrm{v} / \mathrm{v}$ of GAA in water and methanol) were filtered through $0.45 \mu$ membrane filter separately and sonicated to degas. These solvents were transferred in three different reservoirs of the HPLC system.

\section{Preparation of mixed standard solution}

Mixed standard stock solution was prepared by transferring accurately weighed Azadirachta indica $(10 \mathrm{mg})$ and Glycyrrhiza glabra $(10 \mathrm{mg})$ extracts into a volumetric flask $(100 \mathrm{ml})$. Ethanol (50 $\mathrm{ml}$ ) was added to dissolve these extracts and solution was sonicated for $5 \mathrm{~min}$. Then volume was made up to $100 \mathrm{ml}$ with ethanol. This solution was further diluted to obtain $10 \mu \mathrm{g} / \mathrm{ml}$ of each extract.

\section{Study of antimicrobial activity of Azadirachta indica leaves and Glycyrrhiza glabra roots extract}

\section{Preparation of microbiological culture media}

The ampoule of the freeze-dried culture of bacterial strain was procured. The surface of ampoule was disinfected and appropriate precautions were taken during ampoule handling. The ampoule was broken carefully and $2 \mathrm{ml}$ of isotonic solution was added to microbiological culture media. Serial dilutions were prepared from the undiluted solution.

\section{Preparation of mueller hinton agar media}

Media (38 g) was suspended in $1000 \mathrm{ml}$ of distilled water and heated to boil until it gets dissolved completely. Then, it was sterilized by autoclaving at $15 \mathrm{lbs}$ pressure, $121^{\circ} \mathrm{C}$ for $15 \mathrm{~min}$ and cooled to $45-50{ }^{\circ} \mathrm{C}$, mixed thoroughly and poured into sterile petri plates $[23,24]$.

\section{Determination of antimicrobial activity}

The disc diffusion method was used to screen the antimicrobial activity of Azadirachta indica leaves and Glycyrrhiza glabra roots extract on the bacterial strain of Streptococcus mutans [23]. In vitro antimicrobial activity was screened by using Mueller Hinton agar media. After sterilization, the media was transferred to sterilized petri plates aseptically and allowed to stand for $20 \mathrm{~min}$. One $\mathrm{ml}$ of bacterial culture $\left(610 \mathrm{CFU} / \mathrm{ml}, 9^{\text {th }}\right.$ serial dilution $)$ was spread on the surface of agar plates using sterile glass spreader after solidification of agar plates. Sterile discs of Whatman filter papers were used for an antibacterial study. The discs were impregnated with Azadirachta indica leaves extract $(2 \%, 2.5 \%, 3 \%, 3.5 \%, 4 \%, 4.5 \%$ and $5 \%$ $\mathrm{w} / \mathrm{v})[11,25]$, Glycyrrhiza glabra roots extract $(0.5 \%, 1 \% \mathrm{w} / \mathrm{v})[26$, 27], chlorhexidine gluconate $(0.2 \% \mathrm{w} / \mathrm{v})$ solution [28], ethanol as a blank and then carefully placed on the surface of prepared agar plates. The plates were kept for incubation for $24 \mathrm{~h}$ at $37^{\circ} \mathrm{C}$. Zones of inhibition formed around the disc were measured by a transparent scale (in $\mathrm{mm}$ ) at the end of incubation.

\section{Preparation of gel formulation}

Three gel formulations were prepared with different concentrations of carbopol. Initially, methylparaben and propyl paraben solution was prepared in water and then carbopol 934 was soaked in the water for $24 \mathrm{~h}$ followed by neutralization with triethanolamine to $\mathrm{pH} 6.8$ for preparation of gel. Solutions of a measured quantity of extracts of both drugs were prepared in $5 \mathrm{ml}$ of ethanol and added to the gel and then required the quantity of polyethylene glycol (PEG 400) was added [29]. Composition of the mucoadhesive gel is shown in table 1. 
Table 1: Preparation of gel at variable concentration of carbopol 934

\begin{tabular}{|c|c|c|c|c|}
\hline S. No. & Ingredients & F1 & F2 & F3 \\
\hline 1 & Azadirachta indica leaves extract (g) & 2.5 & 2.5 & 2.5 \\
\hline 2 & Glycyrrhiza glabra roots extract (g) & 1 & 1 & 1 \\
\hline 3 & Carbopol $934(\mathrm{~g})$ & 0.4 & 0.6 & 0.8 \\
\hline 4 & PEG $400(\mathrm{ml})$ & 5 & 5 & 5 \\
\hline 5 & Methyl paraben (g) & 0.18 & 0.18 & 0.18 \\
\hline 6 & Propyl paraben (g) & 0.02 & 0.02 & 0.02 \\
\hline 7 & Ethanol (ml) & 5 & 5 & 5 \\
\hline 8 & Triethanolamine $(\mathrm{ml})$ & q. $s$ & q. $s$ & q. $s$ \\
\hline 9 & Distilled water up to $(\mathrm{ml})$ & 100 & 100 & 100 \\
\hline
\end{tabular}

\section{Evaluation of dental gel}

All prepared gel formulations were evaluated for physical appearance, $\mathrm{pH}$, viscosity, spreadability, syringeability, stability study, drug content, diffusion study, in vitro mucoadhesion measurement.

\section{Physical appearance of gel formulations}

Gel formulations were visually inspected for colour, odour, consistency, grittiness, uniformity stickiness and homogeneity [30].

\section{pH measurement}

The $\mathrm{pH}$ of prepared gels was determined using a digital $\mathrm{pH}$ meter. The $\mathrm{pH}$ meter was calibrated before each use with standard $\mathrm{pH} 4$ and $\mathrm{pH} 7$ buffer solutions [30].

\section{Viscosity}

Viscosity of the prepared gels was measured by a Brookfield viscometer at $100 \mathrm{rpm}$, using spindle number 6 . Viscosities were recorded at room temperature [30].

\section{Spreadability}

Spreadability is an important property of dental formulation for patient compliance. About $0.5 \mathrm{~g}$ of gel was placed within a circle of $1 \mathrm{~cm}$ diameter pre-marked on a glass plate over which a second glass plate was placed. A weight of $100 \mathrm{~g}$ was allowed to rest on the upper glass plate. The increase in the diameter due to the spreading of the gels was noted [31].

\section{Syringeability}

Treatment of severe periodontitis required administration of the drug directly into the periodontal pocket by using an injectable system fast relief. In this view, syringeability of gel formulations was evaluated through $21 \mathrm{G}$ needle [30].

\section{Stability study}

Semisolid mucoadhesive dosage form of the optimized batch was selected for the centrifugal test, thermal test, freeze, and thaw test, cooling and heating test $[30,31]$.

\section{Centrifugal test}

The stability of the formulation was studied against the centrifugal force after $48 \mathrm{~h}$ of preparation. The formulation was transferred into tube and centrifuged at $2000 \mathrm{rpm}$ for $60 \mathrm{~min}$ using a centrifugal device and stability of formulation was evaluated at a different time interval $(5,15,30$ and $60 \mathrm{~min})$.

\section{Thermal test}

The stability of formulation was studied against the heat, after $48 \mathrm{~h}$ of preparation. Three samples of the formulation were placed at $4{ }^{\circ} \mathrm{C}, 25^{\circ} \mathrm{C}$ and $45^{\circ} \mathrm{C}$ and evaluated at different time period i.e. $24 \mathrm{~h}, 1 \mathrm{w}$, and $1 \mathrm{mo}$.

\section{Freeze and thaw test}

The stability of the formulation was studied against temperature change, after $48 \mathrm{~h}$ of preparation. Gel formulation ( $15 \mathrm{~g}$ ) was placed at- $8{ }^{\circ} \mathrm{C}$ to freeze it for $48 \mathrm{~h}$ and then thaw at $25^{\circ} \mathrm{C}$ for $48 \mathrm{~h}$ for three cycles.

\section{Cooling and heating test}

The stability of the formulation was studied against temperature changes, after $48 \mathrm{~h}$ of preparation. Gel formulation ( $15 \mathrm{~g})$ was placed at $45^{\circ} \mathrm{C}$ for $48 \mathrm{~h}$ and then $48 \mathrm{~h}$ at $4{ }^{\circ} \mathrm{C}$ for three cycles.

At the end of stability study, the samples were analysed for their physical appearance as colour, $\mathrm{pH}$, and viscosity.

\section{Drug content in dental gel}

Drug content of gel formulation was determined by dissolving gel $(10 \mathrm{mg})$ in about 5-6 $\mathrm{ml}$ of phosphate buffer ( $\mathrm{pH} \mathrm{6.8)}$ and then sonicated for $15 \mathrm{~min}$ in order to obtain complete solubility of drug. The volume of the resultant solution was made up to $10 \mathrm{ml}$ and filtered. The filtrate was further diluted 10 times with phosphate buffer. Drug content was analysed using UV at 214 and $254 \mathrm{~nm}$ [31].

\section{Diffusion study}

In vitro drug release study was carried out using the egg membrane. An egg membrane was stored in phosphate buffer $(\mathrm{pH} 6.8)$ for $24 \mathrm{~h}$ before use. Release of drug from gel formulations was studied using Franz's diffusion cell. An egg membrane was tied to one end of donor compartment. Gel (1 g) was accurately weighed and placed in donor compartment. Receptor compartment was filled with phosphate buffer ( $\mathrm{pH}$ 6.8). Phosphate buffer was agitated using magnetic stirrer and the temperature maintained at $37 \pm 1{ }^{\circ} \mathrm{C} .5 \mathrm{ml}$ of the sample was withdrawn from the reservoir compartment at $15 \mathrm{~min}$ interval and absorbance was measured by UV spectrophotometer at 214 and $254 \mathrm{~nm}$. Each time the reservoir compartment was replenished with the $5 \mathrm{ml}$ volume of phosphate buffer solution to maintain constant volume (Sink condition) [32].

\section{In vitro mucoadhesion measurement}

A significant characteristic of gel is mucoadhesive strength for adhesion to the mucosa in the dental pocket. The mucoadhesion study was carried out using the pig buccal mucosa. The buccal mucosa was stored in phosphate buffer $(\mathrm{pH}$ 6.8) before use. The mucoadhesion study of dental gel formulation was studied using CT3 texture analyser [33-37].

\section{FT-IR analysis of formulation}

FT-IR spectra of Azadirachta indica leaves, Glycyrrhiza glabra roots extract and gel formulation was compared for the presence of the functional group.

\section{RESULTS AND DISCUSSION}

The $\%$ yield was obtained for the Azadirachta indica leaves and Glycyrrhiza glabra roots extract after extraction was found to be 2.25 and $11.2 \%$, respectively. Results of Physicochemical characteristics of Azadirachta indica leaves and Glycyrrhiza glabra roots extract are shown in table 2.

Menstruum was selected for the extraction of drugs was based on the solubility of the active constituents in it. Results of phytochemical screening showed that alkaloid, steroids, flavonoids, tannins, saponins, amino acids, and terpenoids were present in the extracts of both drugs. However, anthraquinone is absent in the extracts of both drugs. Results obtained by this study are presented in table 3. 
Table 2: Physicochemical characteristics of both drug extract

\begin{tabular}{|c|c|c|c|}
\hline S. No. & Characteristics & Azadirachta indica leaves extract & Glycyrrhiza glabra roots extract \\
\hline 1 & Colour & Greenish & Brown \\
\hline 2 & Odour & Typical & Faint and characteristics \\
\hline 3 & Consistency & Sticky & Sticky \\
\hline 4 & $\mathrm{pH}$ & 4.6 & 4 \\
\hline
\end{tabular}

Table 3: Phytochemical screening of the of both drugs extract

\begin{tabular}{|c|c|c|c|}
\hline \multirow[t]{2}{*}{ S. No. } & \multirow[t]{2}{*}{ Phytochemicals } & \multicolumn{2}{|l|}{ Inference* } \\
\hline & & Azadirachta indica leaves extract & Glycyrrhiza glabra roots extract \\
\hline 1 & Alkaloids & $(+)$ & $(+)$ \\
\hline 2 & Steroids & $(+)$ & $(+)$ \\
\hline 3 & Tannins & $(+)$ & $(+)$ \\
\hline 4 & Flavonoid & $(+)$ & $(+)$ \\
\hline 5 & Amino acid & $(+)$ & $(+)$ \\
\hline 6 & Anthraquinone & $(-)$ & $(-)$ \\
\hline 7 & Saponins & $(+)$ & $(+)$ \\
\hline 8 & Terpenoids & $(+)$ & $(+)$ \\
\hline
\end{tabular}

${ }^{*}(+)$ denote presence and (-) denote absence of the phytochemical constituent, the total phenolic content of Azadirachta indica leaves and Glycyrrhiza glabra roots extracts were found to be $22.09 \mathrm{mg} / \mathrm{g}$ and $1.693 \mathrm{mg} / \mathrm{g}$., Rf value of nimbin is 0.09 for TLC of Azadirachta indica leaves extract [18] and a light blue spot found in fig. 1 (under UV light) has Rf value 0.08 indicates that nimbin is present in the extract.

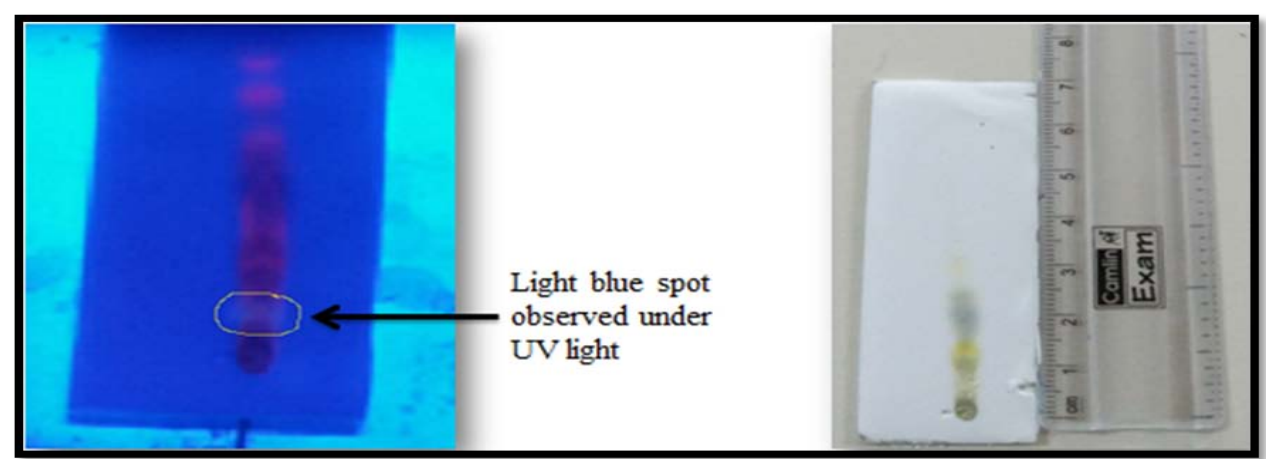

Fig. 1: TLC of Azadirachta indica leaves extract, Rf value of glycyrrhizin is 0.5 for TLC of Glycyrrhiza glabra roots extract [19] and a yellow spot found in fig. 2 has Rf value 0.56 indicates that glycyrrhizin is present in the extract

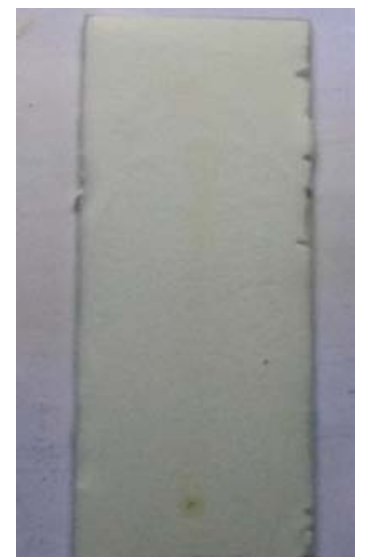

Fig. 2: TLC of Glycyrrhiza glabra roots extract

\section{Optimization of chromatographic conditions}

Isobestic absorbance was observed at 256 and $276 \mathrm{~nm}$ in overlain spectra (fig. 3). Here, $276 \mathrm{~nm}$ was selected as the detection wavelength for HPLC analysis on the basis of results of the preliminary chromatographic trial.

Initially, various chromatographic conditions were tried in order to obtain better separation characteristics by changing the mobile phase composition. Finally, the mobile phase containing acetonitrile: water $(0.1 \% \mathrm{GAA})$ : methanol in the ratio $(30: 60: 10 \mathrm{v} / \mathrm{v})$ was selected at $0.8 \mathrm{ml} / \mathrm{min}$ flow rate and UV detection was done at 276 $\mathrm{nm}$. The values of the retention time of obtained peak for active constituent's nimbin and glycyrrhizin of Azadirachta indica leaves and Glycyrrhiza glabra roots extract were found at 3.119 and 4.157 min, respectively. The chromatogram of mixed standard solutions is shown in fig. 4 and optimized chromatographic conditions are mentioned in table 4 . The values of retention time, theoretical plates and peak tailing factor was found in acceptance criteria.

Table 4: Optimized chromatographic conditions

\begin{tabular}{lll}
\hline S. No. & Parameters & Details \\
\hline 1 & Mobile phase & Acetonitrile: water $(0.1 \%):$ methanol $(30: 60: 10 \mathrm{v} / \mathrm{v})$ \\
2 & Column & Purospher Star RP-18, Hibar C-18 $(250 \mathrm{~mm} \times 4.6 \mathrm{~mm}, 5 \mu \mathrm{m})$ \\
3 & Flow rate & $0.8 \mathrm{ml} / \mathrm{min}$ \\
4 & Column temperature & $30{ }^{\circ} \mathrm{C}$ \\
5 & Detection wavelength & $276 \mathrm{~nm}$ \\
6 & Injection volume & $20 \mu \mathrm{l}$ \\
7 & Run time & $20 \mathrm{~min}$ \\
8 & Retention time & 3.119 (Nimbin) and 4.157 (Glycyrrhizin) \\
\hline
\end{tabular}




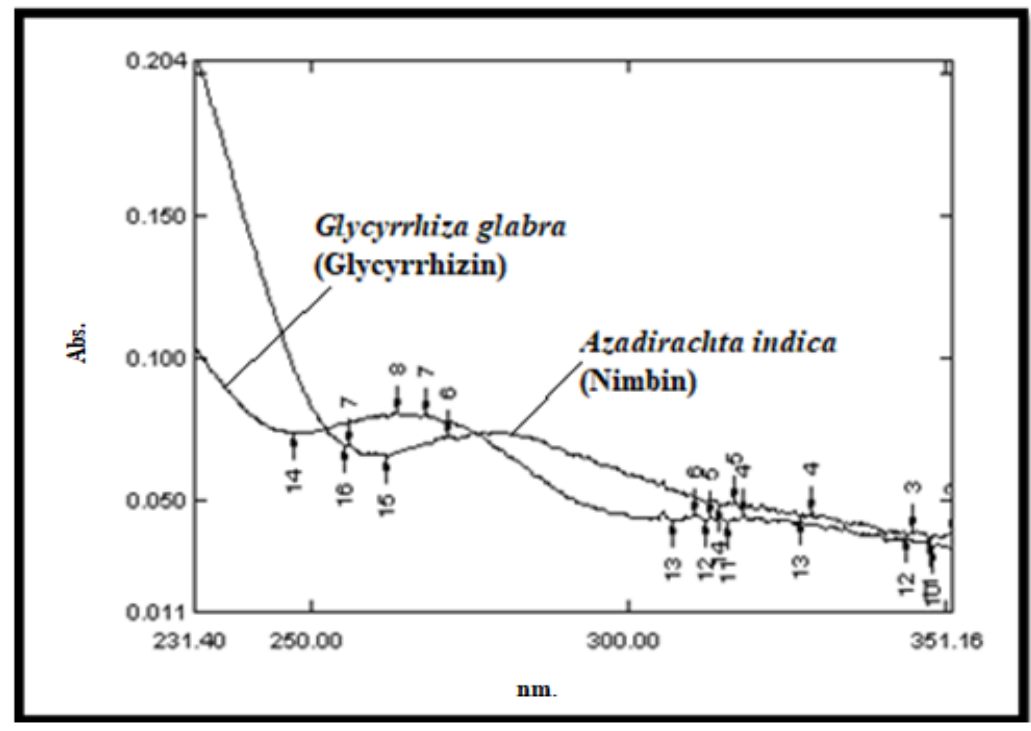

Fig. 3: UV overlain spectra of Azadirachta indica leaves and Glycyrrhiza glabra roots extract

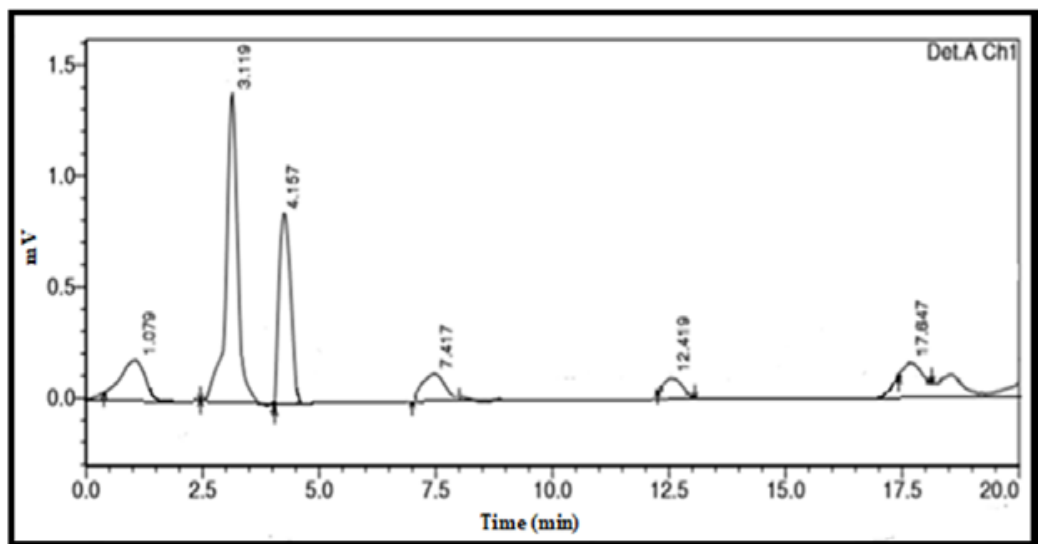

Fig. 4: Typical chromatogram of a mixture of both drug extrat

Results of antimicrobial activity of Azadirachta indica leaves, Glycyrrhiza glabra roots extract and chlorhexidine are shown in table. 5,

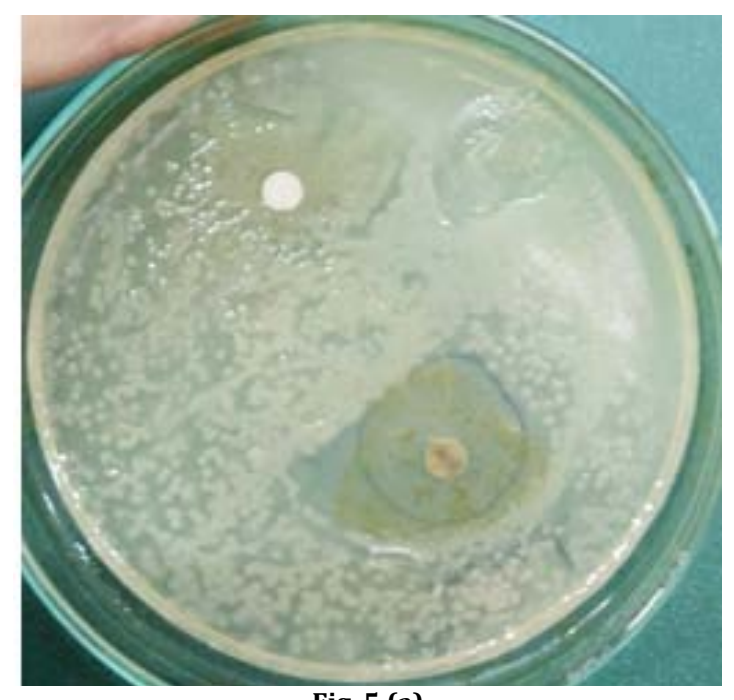

Fig. 5 (a)
Photographs of the zone of inhibition obtained on Mueller Hinton agar plates after antimicrobial activity are shown in fig. 5 (a), (b), (c) and (d).

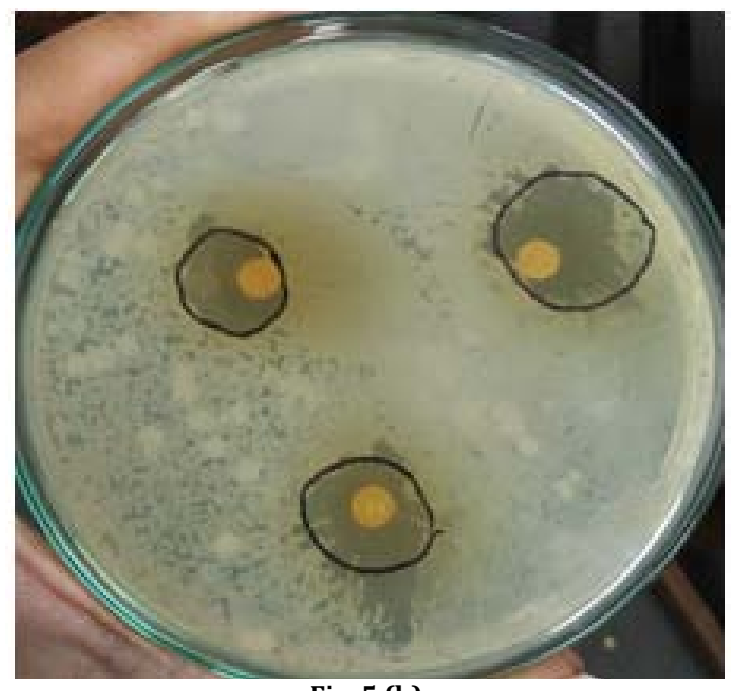

Fig. 5 (b) 


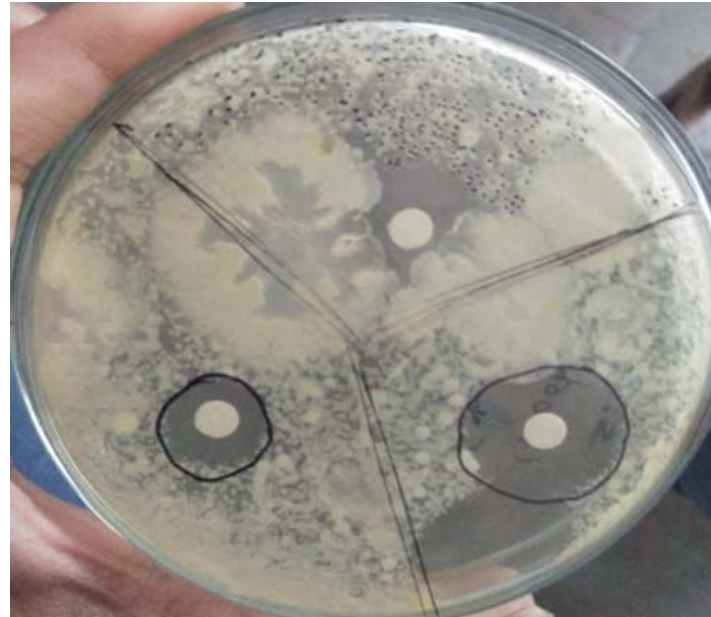

Fig. 5 (c)

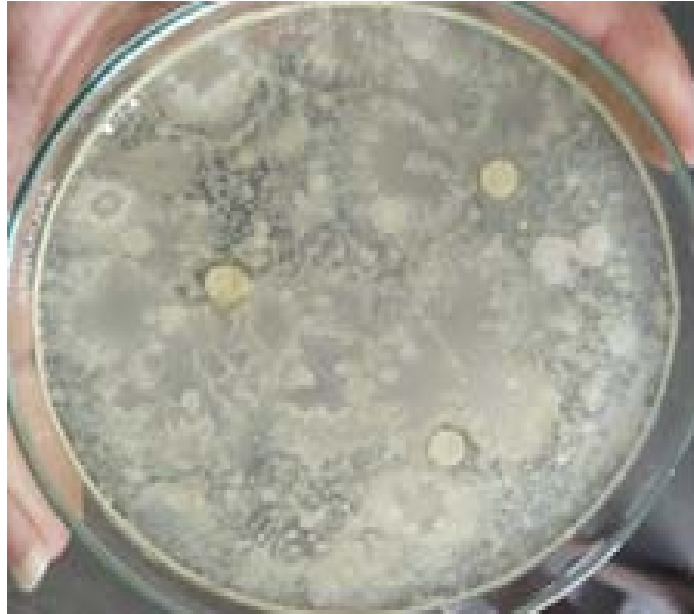

Fig. 5 (d)

Fig. 5: Antimicrobial study (a): $2.5 \%$ w/v Azadirachta indica leaves extract against Streptococcus mutans (b): 1 \% w/v Glycyrrhiza glabra roots extract against Streptococcus mutans (c): $0.2 \% \mathrm{w} / \mathrm{v}$ chlorhexidine gluconate-positive control against Streptococcus mutans (d): Ethanol-negative control (Blank)

Table 5: Antimicrobial activity of Azadirachta indica leaves extract, Glycyrrhiza glabra roots extract and $0.2 \%$ chlorhexidine gluconate solution

\begin{tabular}{|c|c|c|c|c|}
\hline S. No. & Zone of inhibition (ZOI) & $\begin{array}{l}\text { Azadirachta indica leaves } \\
\text { extract }(2.5 \% \mathrm{w} / \mathrm{v})\end{array}$ & $\begin{array}{l}\text { Glycyrrhiza glabra roots } \\
\text { extract }(1 \% \mathrm{w} / \mathrm{v})\end{array}$ & $\begin{array}{l}\text { Chlorhexidine gluconate } \\
\text { [Positive control] }(0.2 \% \mathrm{w} / \mathrm{v})\end{array}$ \\
\hline & Zone of inhibition (mm) & 11 & 10 & 12 \\
\hline \multirow[t]{2}{*}{1} & & 10 & 8 & 11 \\
\hline & & 11 & 9 & 11 \\
\hline 2 & $\begin{array}{l}\text { Mean zone of inhibition } \pm \mathrm{SD}^{*} \\
(\mathrm{~mm})\end{array}$ & $10.66 \pm 0.58$ & $9 \pm 1$ & $11.33 \pm 0.58$ \\
\hline
\end{tabular}

*Data presented are as mean value $\pm \mathrm{SD}, \mathrm{n}=3$.

All concentrations (2 to $5 \% \mathrm{w} / \mathrm{v}$ ) of Azadirachta indica leaves extract to have antibacterial activity against Streptococcus mutans, but $2.5 \% \mathrm{w} / \mathrm{v}$ concentration was selected in the formulation on the basis of adequate inhibition and appropriate taste of extract in the oral cavity. An antimicrobial study indicates that the zone of inhibition obtained by $2.5 \% \mathrm{w} / \mathrm{v}$ extract of Azadirachta indica leaves is closer to the zone of inhibition produced by $0.2 \% \mathrm{w} / \mathrm{v}$ of chlorhexidine. The extract of Glycyrrhiza glabra roots also showed antibacterial activity against Streptococcus mutans and mask the bitter taste of formulations effectively.

Results of evaluation study indicate that the gel formulations have desired properties with respect to their colour, odour, consistency, grittiness, uniformity, stickiness and homogeneity. Results of an evaluation of the physical appearance of dental gels are shown in table 6 .

Table 6: Results of an evaluation of the physical appearance of dental gels

\begin{tabular}{lllllll}
\hline S. No. & Formulation & Colour & Odour & Consistency & Grittiness & Uniformity \\
\hline 1 & F1 & Green & Typical & Smooth & None & Good \\
2 & F2 & Green & Typical & Smooth & None & Good \\
3 & F3 & Green & Typical & Smooth & None & Good \\
\hline
\end{tabular}

The value of $\mathrm{pH}$ of all gel formulations was found in a range of 6.5 to 7.0 and which was in the range of $\mathrm{pH}$ of the site of application. The viscosity of all gel formulations was found in the range 1500 to $3000 \mathrm{cps}$. The average diameter of the spread area for all gels was found in the range of 2 to $3 \mathrm{~cm}$ which indicates that gels are easily spreadable. The result for
pH measurement, viscosity determination, and spreadability are showed in table 7. The results of syringeability study indicated that only F1 and F2 were syringeable through $21 \mathrm{G}$ needle, while F3 was not syringeable. Here, F2 batch was selected as an optimized batch on the basis of stickiness, $\mathrm{pH}$, viscosity spreadability and syringeability.

Table 7: Results of an evaluation of $\mathrm{pH}$, viscosity, spreadability, and syringeability of dental gels

\begin{tabular}{llllll}
\hline S. No. & Formulation & pH & Viscosity (cps) & Spreadability (cm) & Syringeability \\
\hline 1 & F1 & 7 & 1800 & 2.3 & Syringeable \\
2 & F2 & 6.8 & 2500 & 2.4 & Syringeable \\
3 & F3 & 6.5 & 3000 & 2.5 & Not syringeable \\
\hline
\end{tabular}

Entirely the optimized gel formulation was found to be stable upon storage at different temperature conditions for 1 mo. Where no significant changes were observed in the post formulation parameters. The results obtained by the stability study of F2 formulation were shown in table 8. Result of drug content of gel formulation was found to be $83 \%$ of Azadirachta indica leaves and $80.3 \%$ of Glycyrrhiza glabra roots extract, respectively in the gel formulation. 
Table 8: Results of stability study

\begin{tabular}{|c|c|c|c|c|c|}
\hline \multirow[t]{2}{*}{ S. No. } & \multirow[t]{2}{*}{ Stability study } & \multirow[t]{2}{*}{ Conditions } & \multicolumn{3}{|c|}{ Observation } \\
\hline & & & Colour & $\mathbf{p H}^{*}$ & Viscosity* (cps) $^{*}$ \\
\hline \multirow[t]{3}{*}{1} & Centrifuge test & $2000 \mathrm{RPM}(15 \mathrm{~min})$ & Green & 6.8 & 2500 \\
\hline & & 2000 RPM (30 min) & Green & 6.8 & 2500 \\
\hline & & 2000 RPM (60 min) & Green & 6.7 & 2300 \\
\hline \multirow[t]{3}{*}{2} & Thermal test & $4^{\circ} \mathrm{C}(24 \mathrm{~h}, 1 \mathrm{w}, 1 \mathrm{mo})$ & Green & 6.8 & 2500 \\
\hline & & $25^{\circ} \mathrm{C}(24 \mathrm{~h}, 1 \mathrm{w}, 1 \mathrm{mo})$ & Green & 6.8 & 2500 \\
\hline & & $45^{\circ} \mathrm{C}(24 \mathrm{~h}, 1 \mathrm{w}, 1 \mathrm{mo})$ & Green & 6.6 & 2400 \\
\hline \multirow[t]{2}{*}{3} & Freeze and thaw test & $-8{ }^{\circ} \mathrm{C}$ & Green & 6.8 & 2500 \\
\hline & & $25^{\circ} \mathrm{C}$ & Green & 6.8 & 2500 \\
\hline \multirow[t]{2}{*}{4} & Cooling and heating test & $4^{\circ} \mathrm{C}$ & Green & 6.8 & 2500 \\
\hline & & $45^{\circ} \mathrm{C}$ & Green & 6.7 & 2400 \\
\hline
\end{tabular}

${ }^{*}$ Data presented are as mean value, $\mathrm{n}=3$

Drug diffusion study was carried out to calculate the percentage cumulative diffusion of the drug from gel formulation through an egg membrane. The \% cumulative release of Azadirachta indica leaves extract and Glycyrrhiza glabra roots extract from F2 formulation after $120 \mathrm{~min}$ were found to be $87.52 \%$ and $85.43 \%$, respectively as shown in fig. 6.

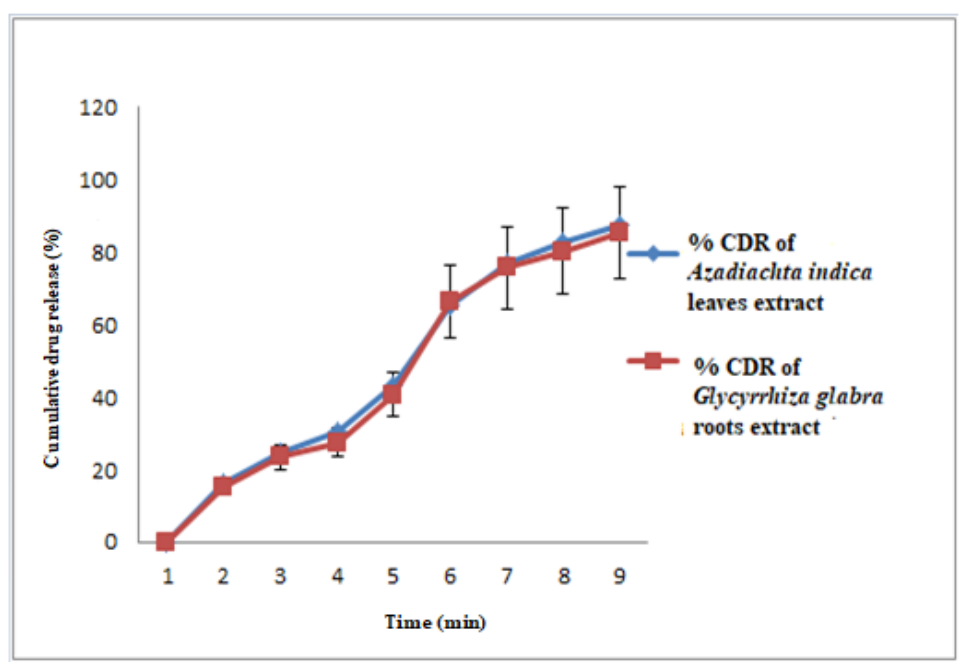

Fig. 6: \% Cumulative drug release from the dental gel

The values of adhesive force and adhesiveness of dental gel was found to be $11.90 \mathrm{~g}$ and 0.92 millijoule, respectively as shown in fig 11. Good gel adhesion to the mucosal surface results in an increase the contact time with the mucosa and prolongation of residence time and better clinical efficacy. The peak area under the positive part of graph indicates good consistency and the peak area under negative part of the graph indicates adhesiveness (more the negative value more the sticky or Mucoadhesive sample) [37].

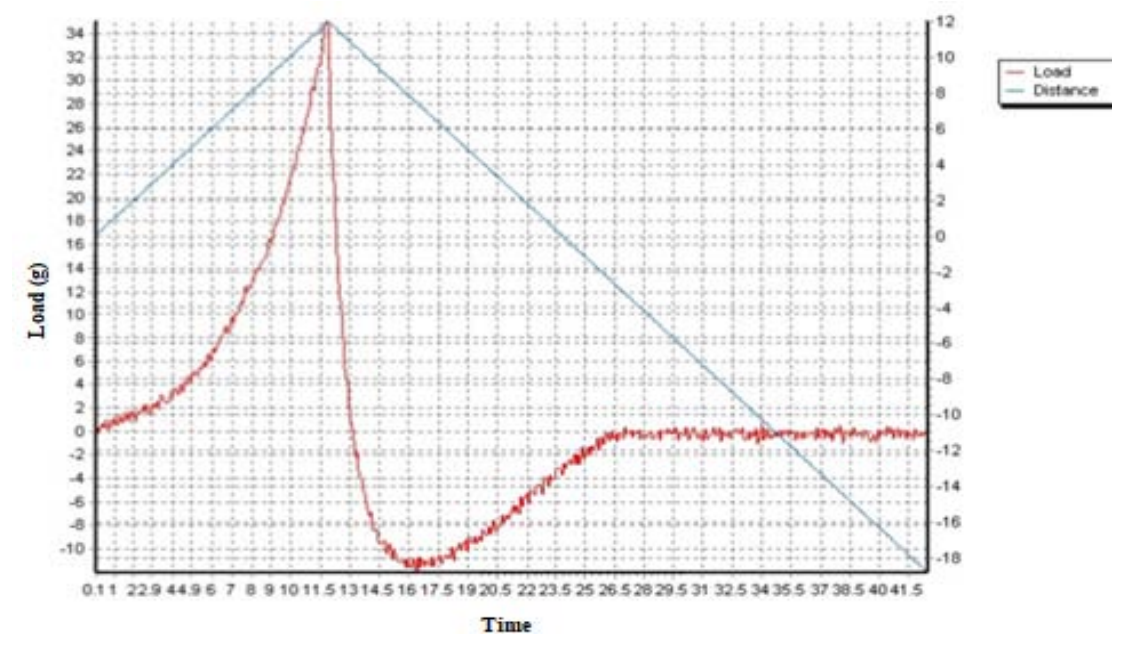

Fig. 7: Mucoadhesion study of formulated gel, the FT-IR spectra for the formulation and extracts are shown in fig. 12. Characteristics peaks obtained for the extract correlated well with that of formulation peaks 


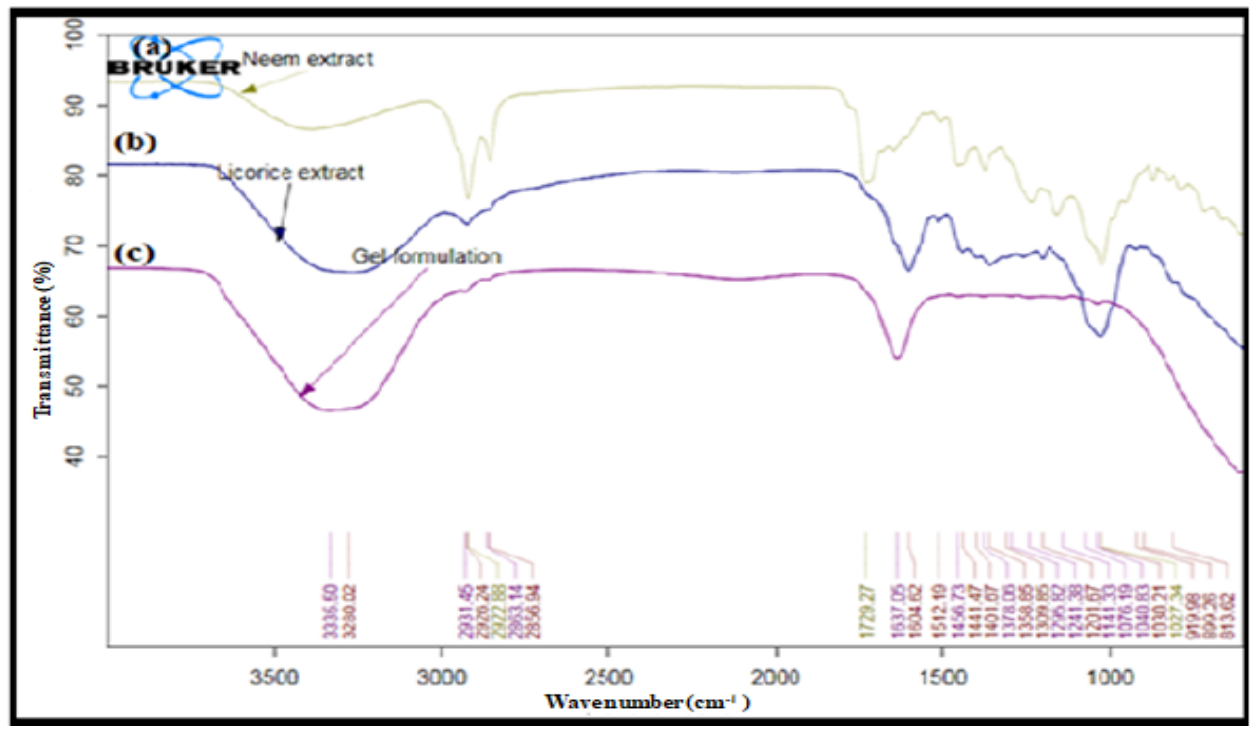

Fig. 8: FT-IR Spectra of (a): FT-IR spectra of Azadirachta indica leaves extract (b): FT-IR spectra of Glycyrrhiza glabra roots extract (c): Semisolid mucoadhesive gel formulation

\section{CONCLUSION}

Results indicate that both extracts have antimicrobial activity. Glycyrrhiza glabra roots extract has an intensive natural sweetener with low-calorie value therefore incorporated in the gel formulation. The evaluation parameters of an optimized batch indicate the prepared dental gel is mucoadhesive, stable, good delivery drug system containing antimicrobial agents for prevention of plaque formation, dental caries, and periodontitis.

\section{AUTHORS CONTRIBUTIONS}

All the authors have contributed equally

\section{CONFLICT OF INTERESTS}

\section{Declared none}

\section{REFERENCES}

1. World Health Organization (WHO). Dental diseases and oral health Geneva WHO; 2003. Available from: http:// www.who.int/oral_health/publications/en/orh_fact_sheet.pdf. [Last accessed on 02 Jan 2018]

2. Microbial disease of mouth and oral cavity. Available from: https://courses.lumenlearning.com/microbiology/chapter/mi crobial-diseases-of-the-mouth-and-oral-cavity/ [Last accessed 10 Jan 2018]

3. Jain N, Jain GK, Javed S, Iqbal Z, Talegaonkar S, Ahmad FJ, et al. Recent approaches for the treatment of periodontitis. Drug Discovery Today 2008;13:932-43.

4. Alshahrani I, Tikare S, Meer Z, Mustafa A, Abdulwahab M, Sadatullah S, et al. Prevalence of dental caries among male students aged 15-17 y in southern Asir, Saudi Arabia. Saudi Dent J 2018. Doi:10.1016/j.sdentj.2018.03.003

5. Nguyen S, Hiorth M. Advanced drug delivery systems for local treatment of the oral cavity. Ther Delivery 2015;6:595-608.

6. Tariq M, Iqbal Z, Ali J, Baboota S, Talegaonkar S, Ahmad Z, et al. Treatment modalities and evaluation models for periodontitis. Int J Pharma Investig 2012;2:106-22.

7. Ananthathavam K, Ramamurthy J. Treating periodontitis with the use of essential oil and herbs. IOSRPHR 2014;4:39-42.

8. Lakshmi T, Krishnan V, Rajendran R, Madhusudhanan N. Azadirachta indica: a herbal panacea in dentistry-an update. Pharmacogn Rev 2015;9:41-4.

9. Carocho M, Morales P, Ferreira IC. Sweeteners as food additives in the XXI century: a review of what is known, and what is to come. Food Chem Toxicol 2017;107:302-17.

10. Mathew AK. Oral local drug delivery: an overview. Pharm Pharmacol Res 2015;3:1-6.
11. Pai MR, Acharya LD, Udupa N. Evaluation of antiplaque activity of Azadirachta indica leaf extract gel-a 6-week clinical study. Ethnopharmacol 2004;90:99-103.

12. Alzohairy MA. Therapeutic role of Azadirachta indica (Neem) and their active constituents in disease prevention and treatment. Evid Based Complementary Altern Med 2016;1-11. http://dx.doi.org/10.1155/2016/7382506

13. Tian M, Yan H, Row KH. Extraction of glycyrrhizic acid and glabridin from licorice. Int J Mol Sci 2008;9:571-7.

14. Al-Hashemi ZS, Hossain MA. Biological activities of different neem leaf crude extracts used locally in Ayurvedic medicine. Pac Sci Rev A: Nat Sci Eng 2016;18:128-31.

15. Al-Jadidi HS, Hossain MA. Studies on total phenolic, total flavonoids and antimicrobial activity from the leaves crude extracts of neem traditionally used for the treatment of cough and nausea. Beni-Suef Univ J Basic Appl Sci 2015;4:93-8.

16. Orujei $Y$, Shabani $L$, Sharifi-Tehrani M. Induction of glycyrrhizin and total phenolic compound production in licorice by using arbuscular mycorrhizal fungi. Russ J Plant Physiol 2013;60:855-60.

17. Kokate CK, Purohit AP, Gokhale SB. Pharmacognosy. $37^{\text {th }}$ ed. Pune: Nirali prakashan; 2015. p. 116

18. Vani MM, Rao PSS, Varma GN, Pushpitha K, Biswal L. Identification and chemical characterization of Azadirachta indica leaf extracts through thin layer chromatography. Int J Res Eng Technol 2016;5:117-22.

19. Senegar NP, Agrawal R, Singh A. A textbook of pharmacognosy. 2nd ed. Hyderabad: Pharma book syndicate; 2009. p. 152-3.

20. Shaikh S, Jain V. Development and validation of a RP-HPLC method for the simultaneous determination of quercetin, ellagic acid and rutin in hydroalcoholic extract of triphala churna. Int J Appl Pharm 2018;10:169-74.

21. Jain HK, Nikam VK. Formulation development and stability indicating HPLC assay of tablets of apixaban. Int J Pharm Pharm Sci 2017;9:24-32.

22. Ranjale AR, Jain HK. Development and validation of RP-HPLC method for simultaneous estimation of cefoperazone and tazobactam in the marketed formulation. Int J Pharm Pharm Sci 2014;6:462-5.

23. Mueller Hinton agar media. Available from: http://himedialabs.com/TD/M173.pdf [Last accessed 03 Feb 2018]

24. Maragathavalli S, Brindha S, Kaviyarasi NS, Annadurai B, Gangwar SK. Antimicrobial activity in leaf extract of neem (Azadirachta indica Linn.). Int J Sci Nat 2012;3:110-3.

25. https://www.uofmhealth.org/health-library/hn-4372000. [Last accessed on 12 Feb 2018]

26. Sharma M, Dwivedi AK. Nutrition neutraceuticals: a proactive approach for healthcare. Nanotechnol Agri-Food Ind 2016;4:79-116. 
27. Sawan MS. Review on taste masking approaches in oral pharmaceutical dosage forms. Leb Med J 2016;1:33-43.

28. Fini A, Bergamante V, Ceschel GC. Mucoadhesive gel designed for the controlled release of chlorhexidine in the oral cavity. Pharmaceutics 2011;3:665-79.

29. Pawar VA, Bhagat TB, Toshniwal MR, Mokashi ND, Khandelwal KR. Formulation and evaluation of dental gel containing essential oil of coriander against oral pathogens. Int Res J Pharm 2013;4:48-54.

30. Aslani A, Ghannadi A, Najafi H. Design, formulation and evaluation of a mucoadhesive gel from Quercus brantii L. and Coriandrum sativum L. as periodontal drug delivery. Adv Biomed Res 2013;2:1-9.

31. Helal DA, El-Rhman DA, Abdel-Halim SA, El-Nabarawi MA. Formulation and evaluation of fluconazole topical gel. Int J Pharm Pharm Sci 2012;4 Suppl 5:176-83.

32. Bisht N, Goswami L, Kothiyal P. Preparation and evaluation of in-situ oral topical gel of levofloxacin by using a combination of polymers. IJOD 2014;2:142-51.

33. Shojaei AH. Buccal mucosa as a route for systemic drug delivery: a review. J Pharm Pharm Sci 1998;1:15-30.
34. Bansal K, Rawat MK, Jain A, Rajput A, Chaturvedi TP, Singh S, et al. Development of satranidazole mucoadhesive gel for the treatment of periodontitis. AAPS Pharm Sci Tech 2009;10:716-23.

35. Sabry SA. Sodium cromoglycate mucoadhesive buccal patches: Design, fabrication, in vitro and in vivo characterization. Int J Appl Pharm 2018;10:76-82.

36. Moldovan M, Lahmar A, Bogdan C, Parauan S, Tomuta I, Crisan $\mathrm{M}$, et al. Formulation and evaluation of a water-in-oil cream containing herbal active ingredients and ferulic acid. Clujul Med 2017;90:212.37.

37. Gel.

https://www.brookfieldengineering.com/applications/texture -applications/personal-care-products/hair-gel. [Last accessed on 20 Feb 2018]

38. Ghosh A, Chakrabarti P, Roy P, Bhadury S, Nag T, Sarkar S, et al. Bioremediation of heavy metals from neem (Azadirachta indica) leaf extract by chelation with dithizone. Asian J Pharm Clin Res 2009;2:87-92.

39. Kannusamy G, Rengaswamy G. Phytochemical constituent and in vitro antibacterial activity of the various extract of Azadirachta indica (Neem). Int J Curr Pharm Res 2016;8:52-5. 